\title{
LAUDATO SI': APORTES ANTROPOLÓGICOS Y ÉTICOS
}

\author{
Pbro. Dr. Amadeo José Tonello ${ }^{1}$ \\ Universidad del Norte Santo Tomás de Aquino, Argentina \\ Recepción: 21.07.2016 ACEPtAción: 30.10 .2016
}

\section{RESUMEN}

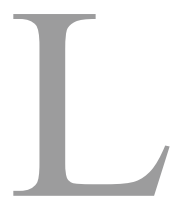

a Encíclica Laudato Sí del Papa Francisco no solo RealiZA IMPORTANTES AFIRMACIONES acerca de las cuestiones ambientales, sino que ofrece también indicaciones muy significativas para la adecuada comprensión de cuestiones antropológicas y éticas relevantes, en particular la ley natural. El presente trabajo intenta mostrar estos aportes y abrir horizontes de diálogo entre la tradición clásica y las posiciones actuales.

Palabras clave: Laudato Si', Papa Francisco, ética, antropología, ley natural.

\section{$L A U D A T O S I^{\prime}:$ A N THROPOLOGICA L A N E THICAL CONTRIBUTIONS}

\begin{abstract}
Pope Francis's Encyclical Laudato Si' makes not only important claims about environmental questions, but also offers very significant suggestions to the right understanding of relevant contemporary anthropological and ethical issues, particularly natural law. The current paper purports to show these contributions and to open horizons of dialogue between the classical tradition and the present ethical stances.
\end{abstract}

Key words: Laudato Si', Pope Francis, ethics, anthropology, natural law.

1 Doctor en Filosofía, Profesor Titular de Ética en la Universidad del Norte Santo Tomás de Aquino, Tucumán, Argentina. Correo electrónico: ajtonello@gmail.com 
En mayo de 2015 ve la luz la segunda (¿o primera?)² encíclica de Francisco, que sugestivamente comienza con las palabras de San Francisco de Asís en su "Cántico de la Creaturas", Laudato Si'. En el presente trabajo me propongo mostrar cómo dicho documento recoge ciertos temas centrales de la antropología filosófica y la ética, y los enmarca en un horizonte más amplio que conecta con el respeto de la naturaleza en su integridad y que se comprende plenamente a la luz de la teología de la creación. Y todo ello en un modo de expresión que lleva en sí la frescura, la originalidad y la inmediata intención pastoral que caracterizan a su autor; asimismo, se trata de un desarrollo que está en plena sintonía con la tradición filosófica y teológica católica sobre el tema.

Alrededor de un año antes, el Papa ya había anunciado su intención de entregar un documento sobre la ecología. Al momento de su publicación, no tardaron en sentirse los ecos, en general positivos, dado que se trata de un tema cuya importancia nadie puede negar, y que viene a reforzar toda una serie de advertencias que diversos factores de la comunidad internacional vienen haciendo sobre el daño del medio ambiente, la utilización inadecuada de los recursos naturales, y otros temas afines. Sin embargo, como suele suceder en la presentación mediática de los documentos eclesiásticos, mucho de lo esencial y profundo quedó de lado, y se puso el acento solamente en lo llamativo y/o polémico.

A mi modo de ver, y esto es lo que el presente trabajo pretende mostrar, Francisco ha logrado no solo llamar la atención sobre ciertos temas importantes de la agenda mundial, sino que ha vuelto a proponer ciertos elementos fundamentales de la moral católica desde una perspectiva nueva, que los hace más comprensibles a la sensibilidad del hombre de hoy.

Entre ellos es destacable el modo en que se pone de relieve la ley natural. Estos aportes de Francisco tienen particular importancia porque el Magisterio de la Iglesia Católica ha usado siempre la ley natural como argumento de fondo para resolver cuestiones éticas de primer orden.

2 Dado que Lumen Fidei, aunque fue publicada por Francisco, fue escrita en su casi totalidad por Benedicto XVI. 
La reflexión filosófica sobre la ley natural se ha visto particularmente enriquecida en las últimas décadas, particularmente con los aportes de estudiosos como J. Maritain, G. Grisez, J. Finnis, M. Rhonheimer, A. M. González, J. Porter, A. MacIntyre, entre otros. (Fernández Labastida - Mercado 2016)

En el ámbito del pensamiento católico, todavía durante el pontificado de Juan Pablo II, el entonces prefecto de la Congregación para la Doctrina de la Fe, el Cardenal Joseph Ratzinger, solicitó a las universidades católicas la realización de congresos sobre la ley natural. De ese pedido surgieron publicaciones en varias lenguas, de diversa calidad y alcance. (Gerardi 2007; Pérez-Soba - Larrú - Ballesteros 2007; Herrera 2008; Cunningham 2009) Benedicto XVI se refirió en diversas ocasiones al tema ${ }^{3}$ y la Comisión Teológica Internacional publicó un documento al respecto en 2009. (Comisión Teológica Internacional 2009)

Sin embargo, la doctrina católica sobre la ley natural, así como sus presupuestos filosóficos, parece haber llegado en los primeros años del nuevo milenio a una especie de callejón sin salida. La causa de esto es que el concepto de ley natural está lejos de ser "posesión pacífica" aun en el terreno de la filosofía. Amplios sectores de la cultura y del pensamiento actual lo han abandonado. Su mismo contenido dista de estar establecido con claridad y precisión. ${ }^{4}$ Aun una figura tan emblemática como Joseph Ratzinger, antes de ser Papa, manifestó vacilaciones sobre la utilidad de un concepto que no parece tener espacio en las coordenadas del pensamiento contemporáneo. ${ }^{5}$

Ante esto, se podría pensar que efectivamente es preciso dejar a un lado una concepción de una ley de la naturaleza, universalmente válida para todos los hombres, y dar cabida a nuevas fundamentaciones de la moral, de las cuales no faltan propuestas en el debate contemporáneo. Más aún, se puede pensar si el decidido rechazo de toda

3 Cfr., simplemente a modo de ejemplo, los discursos del 27-04-2006; 12-02-2007; 24-02-2007; 05-102007; 08-12-2007 (Mensaje por la Jornada Mundial de la Paz del 2008); 18-04-2008 (ante la Asamblea General de las Naciones Unidas); 04-05-2009; 05-06-2010; 15-09-2012.

4 Cfr. sobre todo las posiciones contrapuestas de Alasdair MacIntyre y Jean Porter en CUNNINGHAM, Lawrence (ed.). Intractable Disputes about the Natural Law, cit.

5 Tal como puede apreciarse en su conocido debate con el filósofo alemán Jürgen Habermas, disponible en <http://mercaba.org/ARTICULOS/D/debate_Habermas_Ratzinger.htm>, n. 4 [consultado el 20-072016]. 
una serie de nuevas propuestas de enfoque de la Teología Moral, rechazo que cristaliza sobre todo en la Encíclica Veritatis Splendor de Juan Pablo II, no se encuentra ya superado. Recientemente, los debates en torno a la pastoral del matrimonio y la familia y el nuevo estilo comunicacional del Papa Francisco han generado la idea (ciertamente infundada) de que la Iglesia estaría abandonando muchas de las convicciones tradicionales de su enseñanza moral, que resultarían incomprensibles para la humanidad en este cambio de época.

No obstante, Francisco retoma los conceptos fundamentales de la ética y la antropología cristianas en toda su profundidad, y de modo particular, como mostraremos, el concepto de la ley natural, todo ello en el contexto del cuidado del mundo como casa común, que es el tema central de la encíclica.

\section{1. ¿Cú́l es el enfoque de Francisco en Laudato Si’?}

Es de importancia capital destacar que el enfoque que Francisco hace de la cuestión ambiental es de naturaleza ética. Esta puesta de la ética en el centro del debate es muy significativa, dado que se trata de una disciplina filosófica en estado de crisis. En efecto, en el proceso inacabable de las deconstrucciones nihilistas de fines del S. XX e inicios del XXI la ética parece no encontrar el espacio y la relevancia que ha tenido históricamente, tanto en Occidente como en la cultura humana en general. Para Francisco no se trata meramente de una constatación neutral, sino de un hecho de consecuencias graves: "Ya hemos tenido mucho tiempo de degradación moral, burlándonos de la ética, de la bondad, de la fe, de la honestidad, y llegó la hora de advertir que esa alegre superficialidad nos ha servido de poco.” (Francisco 2015, 229)

Sin duda, esta crisis, que es fuente de violencia y de descuido de la casa común, se relaciona con la pérdida de la mirada contemplativa que denunciaba algunos párrafos atrás (Francisco 2015) y que implica la pérdida del más sano y elemental realismo, (FRANCISCO 2015, 101) aun cuando, más que nunca, debemos recordar que "la realidad es superior a la idea". (Francisco 2013) La degradación ambiental se relaciona estrechamente con la degradación ética (Francisco 2015) y ello exige deci- 
siones responsables, capaces de cambiar la realidad (Francisco 2015). La esperanza siempre aparece como horizonte del obrar humano, que no queda sometido al fatalismo nihilista ni a la esclavitud tecnocrática. (Francisco 2015) La ética, lejos de ser despreciada como una "moralización" impuesta desde afuera a los asuntos de los que se trata, aparece en primer plano, como exigencia para hacer frente adecuadamente a la problemática ecológica, pues esta problemática es de naturaleza esencialmente moral y solo la apelación a la libertad responsable de los hombres puede brindar la clave para hacer frente a los desafíos.

A lo largo de la historia ha habido diferentes enfoques de la ética que han generado “versiones rivales" entre sí. (Macintyre 1992; Abbá 1995) Pero la ética cristiana, tal como la presenta Santo Tomás de Aquino, ha asumido, no sin añadidos y reformulaciones, el enfoque aristotélico, según el cual el fin es determinante de la acción humana y por lo tanto también de la reflexión moral que se ocupa de ella. Pues bien, Francisco en su crítica del utilitarismo consumista, pone de relieve que "tenemos demasiados medios para unos escasos y raquíticos fines"; (Francisco 2015, 203) la pérdida de la dimensión finalista de la moral y su disolución en el mero consumo, o en el vacío posmoderno de sentido, es un problema de fondo que debe ser resuelto si queremos dar algo más que recetas de alcance limitado.

Con el espíritu de la Gaudium et Spes, Francisco nos pone ante la tarea de buscar nuevas síntesis. (Francisco 2015; Concilio Vaticano II 1965) Particularmente insidioso considera al relativismo práctico. (Francisco 2013, 80) Pues la lógica del consumo, del descarte, de la explotación, del daño irresponsable del ambiente, en última instancia responde a un mismo paradigma ético, que pone los deseos del sujeto individual como único criterio irrefutable para medir la acción. (Francisco 2015, 122-123) Ello hace indispensable un sistema normativo con límites infranqueables, (Francisco 2015, 53) que eche sus raíces en convicciones éticas absolutas, (Francisco 2015, 105) para que no resulten una mera carga exterior porque, "cuando es la cultura la que se corrompe y ya no se reconoce alguna verdad objetiva o unos principios universalmente válidos, las leyes solo se entenderán como imposiciones arbitrarias y como obstáculos a evitar". (Francisco 2015, 123) 
En síntesis, Francisco se sitúa dentro de la tradición ética clásica que echa sus raíces en Aristóteles y que en el cristianismo encuentra su expresión más acabada en Santo Tomás. Pues su exposición descansa (entre otros) en los siguientes principios: a) el carácter esencial de la ética, ella es la que da la clave para interpretar y enfrentar la crisis de la "casa común"; b) una ética de la verdad objetiva y de principios universales, de límites infranqueables; c) la necesidad de enriquecer la perspectiva de los fines; d) una racionalidad ética que no puede ser meramente instrumental. (Francisco 2015, 195) Como vemos, estas perspectivas son afines a las que permiten hablar de la existencia y vigencia de una "ley natural". Todo esto no obsta a que presente problemáticas morales nuevas con un lenguaje renovado y congenial a la cultura popular contemporánea, a la vez que introduce con particular firmeza el punto de vista de los pobres, en la más pura tradición del cristianismo.

\section{2. ¿Cuál es la Visión del hombre QUe PResenta LaUdato Si’?}

En su obra "Tres versiones rivales de la ética", MacIntyre intenta resumir la historia del pensamiento moral occidental en la confrontación entre tres grandes paradigmas de la moral: la tradición greco-cristiana, cuyas figuras descollantes son Aristóteles y Santo Tomás; el racionalismo moderno, cuyo producto más simbólicamente representativo es la Enciclopedia, y que desemboca en variedad de enfoques éticos, del formalismo kantiano al utilitarismo en sus diversas variantes (aún teológicas); y el nihilismo, cuya expresión paradigmática se encuentra en el intento nietzscheano de realizar una genealogía de la moral, y que se prolonga en el pensamiento posmoderno.

¿Qué imagen de hombre corresponde a cada uno de estos paradigmas? El hombre del racionalismo es el hombre autónomo de la Ilustración, que se cree capaz de un progreso indefinido gracias a la ciencia y la técnica y que no reconoce límites autoritativos fuera de su razón; el hombre que ha optado por el individualismo, ${ }^{6}$ (Macintyre 1998, 129-130) y que frecuentemente asume posturas éticas de índole utilitarista. El hombre del nihilismo es, por el contrario, el no-hombre que resulta de la sospecha y

6 MacIntyre afirma que el sujeto individualista típico de las filosofías modernas "juega el rol” de individuo, puesto que, en la realidad, el individuo aislado no existe. 
la deconstrucción, que lo reduce a un cúmulo de pulsiones, o a un resultado de las dinámicas económicas, o un punto de intersección de las estructuras sociales, o a una mera accidentalidad de un proceso histórico sin rumbo definido y sin sentido, y que muchas veces termina siendo objeto de "descarte".

Frente a esto es importante descubrir la verdadera imagen del hombre, pues nos advierte el Papa que "no se puede prescindir de la humanidad. No habrá una nueva relación con la naturaleza sin un nuevo ser humano. No hay ecología sin una adecuada antropología". (Francisco 2015; Taylor 1989, 513)

Claramente, Francisco no comparte ni la visión racionalista ni la nihilista. La suya propia es la del hombre creado y redimido en Cristo, como lo expresa en el capítulo II de Laudato Si'. Pero no se enfrenta a las otras de manera neutral. Cuando habla del hombre autónomo que se ve y cree autosuficiente, su reprensión es muy severa, particularmente cuando se refiere a la tiranía del consumo y a la esclavitud del mercado. ${ }^{7}$ Cuando se pone frente al hombre cuya existencia carece de sentido, su mirada aparece más comprensiva: ese hombre es en última instancia el pobre a quien hoy Cristo nos invita a mirar con especial compasión y a dirigir hacia él el impulso de la tarea evangelizadora. Es al que Guardini, en un libro que el Papa cita varias veces en Laudato Si', llama "el hombre no-humano", que vive una relación con la naturaleza mediatizada por el cálculo y el aparato y que cada vez está más preso de una estructura en el que el ámbito de sus vivencias es radicalmente superado por la esfera de sus conocimientos y sus obras. (Guardini 1995, 95)

El hombre del nihilismo ha llegado a ser la imagen fáctica del hombre de hoy. No la imagen verdadera, la querida por el Creador y la renovada por Cristo, pero sí la imagen real del hombre concreto al que la Iglesia debe dirigir la palabra de salvación. Ese hombre es, como decía san Juan Pablo II, "el camino de la Iglesia". (San Juan Pablo II, 1979)

7 Por eso, se quedan cortas las objeciones que se han dirigido a Francisco como reacción a su crítica de la economía de mercado; lo que Francisco cuestiona es una concepción antropológica y no una herramienta económica que, en el debido contexto, puede servir al progreso de la humanidad. 
Tal vez cabría preguntarse si no hay un toque de ingenuidad en esta visión. Pues el hombre de la posmodernidad, aun en medio de su disolución nihilista, reivindica el horizonte de la pura decisión, del relativismo, del pensamiento débil, como el auténtico punto de vista ético, en un posicionamiento no exento de contradicciones. El hombre de hoy sigue siendo moderno en sus principios inspiradores, aunque sea posmoderno en su desilusión, sus frustraciones y su escepticismo. Pero Francisco decide correr el riesgo pastoral de esa simpatía por el hombre posmoderno como una apuesta audaz aunque no exenta de ambigüedades. ${ }^{8}$

Francisco nos presenta al hombre como creatura de Dios amada por sí misma. (Francisco 2015, 65) Es un ser vincular, cuya existencia se define en base a tres grandes relaciones: con Dios, con los demás, con la naturaleza. (Francisco 2015, 66) Poniendo especial énfasis en las dos últimas, Francisco transmite la idea de una fraternidad universal. (Ratzinger 2015, 3-65) La experiencia de san Francisco de Asís invita a ver esa fraternidad extendida a todas las creaturas, (Francisco 2015, 11) poniéndonos frente a la realidad con una actitud de estupor y maravilla. Ello, sin embargo, no implica el absurdo biocentrismo que lleva a desconocer el lugar propio del hombre en el mundo, pues, aunque dañar el ambiente es como dañarnos a nosotros mismos, "esto no significa igualar a todos los seres vivos y quitarle al ser humano ese valor peculiar que implica al mismo tiempo una tremenda responsabilidad”. (Francisco 2015, 90)

La comunión interpersonal se da ante todo en la complementariedad de los sexos (Francisco 2015, 155) y en esta afirmación, como la que veremos más adelante en el n.155, queda clara la intención de Francisco de proponer una ecología integral. La fraternidad, antes de ser una tarea, es ya una realidad y un don que deriva de la misma creación. El don gratuito de la fraternidad inspira la respuesta gratuita del amor fraterno. (Francisco 2015, 228) La fraternidad no es una utopía: se ha hecho realidad por el amor redentor de Cristo y, por eso, es una tarea que se asume desde la esperanza. Somos una sola familia humana. (Francisco 2015)

8 Como las que se traslucen en la Exhortación Apostólica Amoris Laetitia (desde ahora AL), del 19-3-2016, respecto de la conciencia que subjetivamente puede sentirse tranquila aun cuando objetivamente esté en el error. ¿No es esa una concesión al hombre "moderno", seguro de sí y que decide los valores morales en la subjetividad de su conciencia, más que un gesto de misericordia para el "posmoderno", "pobre" y desprovisto de sentido en su vida? 
El hombre se presenta igualmente en unión con la naturaleza, porque él mismo es "tierra", como dice el Génesis. (Francisco 2015) Asimismo, la ruptura del hombre con su hermano conlleva necesariamente la ruptura con la tierra, como el mismo libro del Génesis lo pone de manifiesto en el relato de Caín y Abel.

Tres principios más terminan de delinear la antropología que nos propone Francisco: ante todo, la conciencia de la apertura del hombre a la verdad, a la belleza, al bien. Ese núcleo íntimo que es el alma humana no es una realidad cerrada, sino una estructura constitutivamente abierta con una capacidad infinita que no puede ser cancelada por ningún poder y que permanece siempre como signo indeleble de la dignidad humana y de su trascendencia. Esa dignidad que aparece renovada en cada hombre que viene a este mundo es también la señal que nos invita a la esperanza, a saber, que, en medio de un panorama tan oscuro, "no todo está perdido". (Francisco 2015, 205) Luego, tenemos el principio personalista, afirmado repetidas veces en contraposición al individualismo del hombre racionalista, autónomo y autosuficiente. Principio personalista que implica a la vez el valor de cada uno y su necesaria vinculación a los otros, y el valor de la persona por encima de cualquier otra realidad creada, como antes vimos. Y la persona se entiende como realidad esencialmente relacional, según la enseñanza que desde el misterio de la Trinidad se proyecta sobre la antropología: "la persona humana más crece, más madura y más se santifica a medida que entra en relación, cuando sale de sí misma para vivir en comunión con Dios, con los demás y con todas las criaturas". (Francisco 2015, 240) Finalmente, la relación del hombre con la naturaleza se expresa en la metáfora bíblica del administrador, que tiene potestad a la vez que responsabilidades, y que debe rendir cuentas: "la forma correcta de interpretar el concepto del ser humano como 'señor' del universo consiste en entenderlo como administrador responsable”. (Francisco 2015, 116)

\section{Visión de la NATURALEZa}

Con los elementos que hemos recogido hasta ahora, podemos trazar los rasgos fundamentales con que Francisco describe a la naturaleza. Cuestión capital, no solo porque hace referencia al tema central de la encíclica, sino porque de la visión de la 
naturaleza que cada uno tiene dependen muchas opciones éticas y particularmente, la plausibilidad de la noción de ley natural.

Pero existe un problema previo: aún dentro de la visión clásica, la palabra "naturaleza" tiene una pluralidad de significados, que a veces son divergentes entre sí. Puede significar el principio de ser y de obrar de una determinada realidad, y así podemos hablar de naturaleza racional, naturaleza angélica o naturaleza divina; o, por el contrario, puede referirse al mundo de lo inanimado que sigue unas leyes y un determinismo propios, y que se opone al mundo de la razón, de la libertad, de la cultura, de la historia. En este último caso, la naturaleza configura un mundo que es para el hombre a la vez un límite y una oportunidad, una cantera de materiales sobre los cuales puede ejercer su acción. Sin contar con los vaivenes modernos del sentido de naturaleza, que pasa de ser creación divina a realidad corrompida en ciertas visiones teológicas, o queda canonizada en una visión naturalista y secularizada, desgajada del dogma del pecado original, y así convertida en principio normativo en su facticidad inmediata.

En realidad, la contraposición entre los dos sentidos de naturaleza (naturaleza como esencia dinámicamente considerada, y naturaleza como el mundo de lo no humano) es menos tajante de lo que parece, dado que en ambos casos hablamos de un "lógos", de una razón, de un sentido que subyace a toda la realidad. Naturaleza es razón en acción, es lógica en movimiento, es sentido en realización. Solo que se trata de un sentido que no emana de la razón humana, sino que le es dado y que ella debe descubrir. Si es mucho pedir al hombre del S. XXI que acepte un sentido de las cosas que no ha sido impuesto por él mismo, hay que saber que solo así podrá superar el callejón sin salida del sinsentido nihilista.

La naturaleza según Francisco es creatura de Dios dotada de sentido y valor en sí misma. Así, se opone a la visión racionalista, según la cual la naturaleza es mero material a ser plasmado por el hombre, con una potencialidad virtualmente infinita; y también al vitalismo de algunas ideologías posmodernas, que confieren una sustancialidad indebida a la naturaleza (lo que Francisco llama "biocentrismo"). (Francisco 2015, 118) 
La racionalidad de la naturaleza aparece varias veces expresada con la metáfora del "libro", (Francisco 2015, 4) que conecta con los padres de la ciencia moderna, como Galileo, (Galilei 1981, 63) y que nos coloca en la perspectiva de una hermenéutica dialógica con tres factores relevantes, el que escribe el libro, el que lo lee e interpreta, y la racionalidad propia de ese libro, que el Concilio Vaticano II reconoció como la "autonomía de las cosas terrenas": "Por la propia naturaleza de la creación, todas las cosas están dotadas de consistencia, verdad y bondad propias y de un propio orden regulado que el hombre debe respetar".

Sin embargo, para Francisco el concepto decisivo no es el de naturaleza, sino el de creación:

Para la tradición judío-cristiana, decir ‘creación’ es más que decir naturaleza, porque tiene que ver con un proyecto del amor de Dios donde cada criatura tiene un valor y un significado. La naturaleza suele entenderse como un sistema que se analiza, comprende y gestiona, pero la creación solo puede ser entendida como un don que surge de la mano abierta del Padre de todos, como una realidad iluminada por el amor que nos convoca a una comunión universal. (Francisco 2015, 76)

La racionalidad íntima de la naturaleza aparece en sintonía con el poder y el amor de un Padre cuyo designio es la armonía del todo. La creación implica no solo el sistema lógico de la naturaleza, sino un gesto permanente de amor. No es solo un libro a leer e interpretar, sino la prenda de una relación interpersonal entre Dios y los hombres.

Como ya dijimos, en $L S$ Francisco utiliza, en varios pasajes, los análisis del sacerdote y filósofo ítalo-alemán Romano Guardini, tomados de su libro "El fin de la modernidad" El antropocentrismo moderno ha gestado una relación equivocada con la naturaleza, a la que "ni siente como norma válida, ni menos aún como refugio viviente. La ve sin hacer hipótesis, prácticamente, como lugar y objeto de una tarea en la que se encierra todo, siéndole indiferente lo que con ello suceda". (Francisco 2015, 83) La pérdida del vínculo vital y profundo con el mundo se ve favorecida por el distanciamiento de la realidad natural que provoca la técnica, y que vuelve al 
hombre un ansioso buscador de sensaciones, incapaz de valorar el mundo si no es por el rédito inmediato de utilidad que ofrece a sus deseos. Ello, según Francisco, se vio favorecido por una equivocada presentación de la antropología cristiana, que promete al hombre un dominio absoluto sobre la creación, (Francisco 2015, 108) haciéndole perder de vista su lugar propio como administrador. El poder por el mismo poder, el afán de dominio, utilidad y eficiencia, "cosifican" a la naturaleza, siendo que ella porta un mensaje escrito por Otro que a través de ella se quiere hacer escuchar. (Francisco 2015, 105) Es especialmente significativa la síntesis del n. 117:

La falta de preocupación por medir el daño a la naturaleza y el impacto ambiental de las decisiones es solo el reflejo muy visible de un desinterés por reconocer el mensaje que la naturaleza lleva inscrito en sus mismas estructuras. Cuando no se reconoce en la realidad misma el valor de un pobre, de un embrión humano, de una persona con discapacidad -por poner solo algunos ejemplos-, difícilmente se escucharán los gritos de la misma naturaleza. Todo está conectado. Si el ser humano se declara autónomo de la realidad y se constituye en dominador absoluto, la misma base de su existencia se desmorona". (Francisco 2015, 117)

Aquí se plantea, sin embargo, la pregunta de hasta qué punto le es lícito al hombre intervenir sobre la naturaleza. Francisco afirma que es válida una intervención humana que acompaña y se pliega a las posibilidades que ofrecen las cosas mismas, como recibiendo lo que la naturaleza puede dar de suyo. Pero no es legítimo "extraer todo lo posible de las cosas por la imposición de la mano humana, que tiende a ignorar $\mathrm{u}$ olvidar la realidad misma de lo que tiene delante”. (Francisco 2015, 106) Ahora, ¿con qué criterios se establece la línea demarcatoria entre una y otra actitud? Se trata de un problema ético aún a explorar. Por ejemplo, ¿hasta qué punto se pueden modificar genéticamente los seres vivos sin que ello implique un avance abusivo sobre la naturaleza y un daño quizá irreversible al medio ambiente? ¿Y cuáles deberían ser los límites de las intervenciones de ese tipo sobre los seres humanos?

Sin que se pueda dar una solución válida para todos los casos, lo cierto es que solo una adecuada hermenéutica de la creación puede darnos las claves últimas para es- 
tablecer una justa relación con la naturaleza. Una pista para interpretar esos límites puede estar dada por la necesidad de evitar los daños ambientales que hacen imposible la vida humana en un determinado contexto, procurando una vez más descubrir la creación como casa común y a nosotros mismos como parte de ella, y no como mera materia prima para la satisfacción de los deseos del individuo.

\section{En LA ENCRUCIJAda de laS étiCaS}

Nuestro tiempo se caracteriza por presentar una gran variedad de enfoques éticos, muchas veces discordantes y hasta aparentemente irreconciliables, que se expresan en diversas opciones y realizaciones culturales. Dichas opciones a veces son asumidas acríticamente por las masas y difundidas e impuestas a través de las mediaciones de la cultura globalizada. Por ello, tanto más se hace necesario evaluarlas críticamente ¿Qué posición ocupa la LS en la encrucijada de las éticas?

Ante todo, resulta claro que, en la línea del Magisterio reciente, la opción principal es la personalista, que, a la vez que recoge las mejores conclusiones filosóficas en esa línea, se presenta en síntesis armoniosa con la tradición moral filosófica y teológica. Como aportación propiamente cristiana, está el tener en cuenta el punto de vista de los pobres que se erige en principal y determinante para la validez de toda opción ética.

¿Cuáles son las corrientes éticas modernas a las cuales Francisco se opone? Ante todo, el utilitarismo en sus diversas variantes, que en sus modernas versiones capitalistas privilegia la eficiencia por encima de todo y reconoce al mercado, como entidad autónoma, un poder autorregulatorio que ha sido desmentido muchas veces por los hechos. (Francisco 2015, 190) En el fondo está la concepción de una racionalidad instrumental que la pone al servicio de la satisfacción de deseos individuales y desconoce su nativa inclinación a la verdad y al bien. (Francisco 2015, 195; 205)

El relativismo, cuyo poder disolvente se viene experimentando de manera persistente en la cultura globalizada, merece también una valoración negativa, ratificando las expresiones anteriores del Magisterio. (Francisco 2015, 123) 
Por otra parte, Francisco se manifiesta abierto a las instancias que proceden de las éticas del consenso, dado que el diálogo entre los diferentes factores se revela necesario para obtener los acuerdos que permitan avances reales para la resolución de problemas globales. El diálogo, como resulta claro de lo anterior, no implica el abandono o la relativización de las propias convicciones, sino que toma a estas como punto de partida para el ensayo de respuestas a problemas complejos, muchas veces con facetas técnicas, para los que la Iglesia no pretende tener todas las soluciones. (Francisco 2015, 165; 173; 188)

El progresismo, ideología cuasi mítica típica de la Edad Moderna y que hoy aún ejerce su influjo en la política, la economía y la cultura, es criticado igualmente por la Encíclica. Sobre todo, en su faz económica, donde se hace necesario redefinir el progreso (Francisco 2015, 194) y aún “desacelerar”. (Francisco 2015, 191) Nuevamente se plantea la cuestión del sentido del progreso, que aparece sintéticamente expresada en la “subordinación de la economía a la política, y de esta a la ética”. (Francisco 2015, 189)

En este sentido, la ciencia y la técnica no pueden por sí solas dar una respuesta a la cuestión del sentido, porque dicha cuestión excede sus competencias. Hay una contaminación ideológica de la ciencia, que aparece por ejemplo en un evolucionismo ciego, en que "la persona humana es considerada solo un ser más entre otros, que procede de los juegos del azar". (Francisco 2015, 118) La insuficiencia de la ciencia y de la técnica implica igualmente la necesidad de abrirnos a las instancias que proceden de las tradiciones espirituales y religiosas. (Francisco 2015, 199-200)

En la encrucijada de las éticas, Francisco no pretende tan solo colocar la visión de la Iglesia como un interlocutor más de un debate teórico, sino que propone toda una pedagogía ética destinada a la formación de hábitos que desde el interior de las personas se constituyan en una fuerza transformadora de la cultura. (Francisco 2015)

En síntesis, la ética que Francisco propone es vincular y personalista, basada en valores objetivos, abierta a la comunión, confiada en la capacidad de la libertad humana para transformar la historia, opuesta al consumismo y al materialismo, exenta de la tentación cientificista. 


\section{Ley NATURAL}

En todo este contexto resulta perfectamente coherente la visión de la ley natural que nos expone $L S 155$ :

La ecología humana implica también algo muy hondo: la necesaria relación de la vida del ser humano con la ley moral escrita en su propia naturaleza, necesaria para poder crear un ambiente más digno. Decía Benedicto XVI que existe una «ecología del hombre» porque «también el hombre posee una naturaleza que él debe respetar y que no puede manipular a su antojo». En esta línea, cabe reconocer que nuestro propio cuerpo nos sitúa en una relación directa con el ambiente y con los demás seres vivientes. La aceptación del propio cuerpo como don de Dios es necesaria para acoger y aceptar el mundo entero como regalo del Padre y casa común, mientras una lógica de dominio sobre el propio cuerpo se transforma en una lógica a veces sutil de dominio sobre la creación. Aprender a recibir el propio cuerpo, a cuidarlo y a respetar sus significados, es esencial para una verdadera ecología humana. También la valoración del propio cuerpo en su femineidad o masculinidad es necesaria para reconocerse a sí mismo en el encuentro con el diferente. De este modo es posible aceptar gozosamente el don específico del otro o de la otra, obra del Dios creador, y enriquecerse recíprocamente. Por lo tanto, no es sana una actitud que pretenda 'cancelar la diferencia sexual porque ya no sabe confrontarse con la misma'. (Francisco 2015, 155)

Merece la pena dedicar un análisis a este párrafo. El concepto de ecología humana hace referencia a que, así como los seres vivos constituyen sistemas cuyas reglas es preciso conocer y respetar, también el ser humano es un sistema abierto con una precisa estructura, delicados equilibrios y potentes dinamismos que se expresan en "la ley moral escrita en su propia naturaleza". La ley natural no implica negación de la racionalidad, libertad o autonomía humanas, sino saber situarlas en su justo punto incluyendo el mensaje específico que nos da nuestro propio cuerpo en su dualidad de masculinidad y femineidad. 
De tal modo, la "ecología humana", concepto ya acuñado por Juan Pablo II, (Francisco 2015,5$)$ permite introducir armoniosamente el mensaje de la ley natural, que se presenta como aquel bagaje con el que partimos en la andadura de la propia historia, la orientación fundamental que permite al hombre distinguir lo bueno de lo malo.

La naturaleza no es algo separado de nosotros, pues estamos incluidos en ella, somos parte de ella y estamos interpenetrados. (Francisco 2015, 139) Por eso es necesario, para orientarnos adecuadamente en la aventura moral de nuestra historia, escuchar su voz, descubrir su mensaje, atender a sus instancias. Laudato Si' enriquece, por lo tanto, el clásico concepto de la ley natural, y nos hace redescubrir la imagen del hombre como un ser con un profundo arraigo ontológico. Las grandes direcciones de la ley natural (hacia Dios, hacia el matrimonio y familia, hacia la educación de los hijos, hacia la vida social) (Santo Tomás De Aquino) se desarrollan en la toma de conciencia del profundo vínculo que une al ser humano con el medio, del cual él mismo es siempre parte.

Todo esto implica una serie de aplicaciones concretas, que retoman las grandes convicciones que forman parte del mensaje moral cristiano. A pesar de la visión a veces sesgada de los medios masivos de comunicación, en Francisco dichas convicciones se encuentran expresadas con fuerza y decisión. Ya hemos visto en el n. 155 la referencia a la necesidad de descubrir el mensaje contenido en la masculinidad y feminidad, y de asumirlo plenamente, lo cual va contra la insistente prédica de la ideología de género. (Exhortación Apostólica Amoris Laetitia 2016) Pero hay otras conclusiones concretas que se derivan de esta reafirmación de la ley natural. Por ejemplo, en lo que se refiere al aborto nos dice:

Tampoco es compatible la defensa de la naturaleza con la justificación del aborto. No parece factible un camino educativo para acoger a los seres débiles que nos rodean, que a veces son molestos o inoportunos, si no se protege a un embrión humano, aunque su llegada sea causa de molestias y dificultades. (Francisco 2015, 120) 
Por todo esto, no extraña que un concepto central del capítulo IV, que propone una ecología integral, sea el del bien común. Este no consiste simplemente en la suma y distribución de los bienes materiales, sino que abarca un campo mucho más amplio, es "el conjunto de condiciones de la vida social que hacen posible a las asociaciones y a cada uno de sus miembros el logro más pleno y más fácil de la propia perfección". (Francisco 2015, 156; Concilio Vaticano II 1965) El bien común implica el respeto a la persona humana como tal, en el respeto a sus derechos inalienables y en su ordenación a un desarrollo integral. Igualmente, el bienestar social y el desarrollo de los diversos grupos intermedios, especialmente la familia, aplicando el principio de subsidiaridad. Finalmente, incluye necesariamente la paz social. (Francisco 2015, 157) $Y$ ante la inequidad e injusticia imperantes, el bien común se convierte en llamado a la solidaridad y opción preferencial por los más pobres. (Francisco 2015, 158) El principio del bien común expone un panorama ético que apunta a la totalidad de la vida, y no solamente a la resolución de algunas problemáticas relacionadas con la sustentabilidad económica o ambiental. En el mismo sentido es destacable el modo en que Francisco desarrolla el concepto de "justicia intergeneracional", (Francisco $2015,159)$ pues nos pone ante la proyección de nuestros vínculos con los demás, en la dinámica del don, y por ello supera infinitamente la mera perspectiva del cálculo racional de ganancias.

\section{Conclusión}

La encíclica Laudato Si' representa un hito fundamental en el Magisterio Pontificio por varias razones. Una de ellas es que por primera vez se aborda en un documento papal de máxima jerarquía el tema de la ecología y el cuidado del medio ambiente, desde una visión filosófica y teológica enteramente coherente con el depósito de la fe. Pero quizá más importante aún resulta el que en ella se vuelvan a proponer algunas de las convicciones éticas más importantes de la Tradición católica. Me detendré, en particular, en lo que se refiere a la ley natural, pues considero que Francisco hace un significativo aporte al debate ético contemporáneo. 
Pues, la ley natural ya no puede ser presentada como la conciencia inmediata de ciertos valores morales que se deducen automáticamente de la naturaleza humana y que son evidentes para todos. Al contrario, la ley natural aparece como la voz de la naturaleza que resuena en la conciencia del hombre de un modo particularmente fuerte ante las tremendas perspectivas que presenta el daño del medio ambiente, la dilapidación irresponsable de los recursos naturales, la degradación de la vida humana en todas sus dimensiones. Una voz que reclama una respuesta integral y éticamente centrada en el hombre como persona, capaz de descubrir valores de vigencia permanente más allá de lo cambiante (Concilio Vaticano II 1965, 10) y estrechamente relacionado con Dios, con sus semejantes y con el medio. Una voz que se dirige al hombre y lo invita a entrar en diálogo con Dios, en el recinto íntimo de su conciencia, entendida esta no como la instancia monológica donde el individuo decide qué es el bien y qué es el mal, sino como el espacio de encuentro del hombre con los valores que vienen de una dimensión trascendente. (Concilio Vaticano II 1965, 16) Y por eso, no hay en la enseñanza de Francisco una relativización o abandono de las convicciones éticas fundamentales (valor de la persona, de la vida humana desde la concepción, matrimonio entre varón y mujer); más bien, nos ofrece un horizonte más amplio para comprenderlas, dado que en el panorama del pensamiento contemporáneo muchas de las condiciones necesarias para la comprensión de los bienes morales que esas convicciones encierran, se encuentran oscurecidas y de hecho abandonadas.

Por eso, Laudato Si' es una invitación al diálogo con la humanidad. (Francisco 2015, 163-201) Ese diálogo encuentra su oportunidad en una serie de problemas que son urgentes y que no se pueden dejar de lado, y a la vez implica reafirmar vigorosamente y sin concesiones los principios fundamentales de la ética cristiana. Los análisis aquí apenas esbozados pueden abrirse a un nuevo intento de proponer la idea de la ley natural, que sea capaz de superar las dificultades que provienen de las críticas contemporáneas, así como de integrar las nuevas perspectivas éticas que presenta nuestro tiempo. Frente a una de las objeciones más corrientes contra la ley natural (su presunta intolerancia frente a los que no comparten sus postulados éticos), Laudato $S i$ ' representa la "propuesta de diálogo", que es el modo en que hoy debería presentarse la ley natural y no como mera imposición externa. 
En efecto, la ley natural es el conjunto de los principios morales fundamentales, más o menos inmediatamente accesibles a todos los hombres, pero en la práctica, muchas personas son capaces de ver solo las "semillas" de dichos principios, sin llegar a extraer de ellos todas las consecuencias prácticas. Esta presentación de la ley natural como "propuesta" de diálogo no significa convertir en "optativas" sus prescripciones; más bien implica encontrar los caminos a través de los cuales dichas prescripciones puedan ser comprendidas por todos. Dicho de otro modo, la ley natural es "intolerante" frente a la conculcación de ciertos principios que son ineludibles y absolutos, pero el modo de presentarla debe ser "tolerante" con las personas, a las que debe ayudar gradualmente a desenmascarar los errores teóricos y los condicionamientos prácticos que impiden el reconocimiento efectivo de los principios más fundamentales. Pues en toda persona humana están esas semillas de las verdades morales y, como en el paciente trabajo del agricultor, es preciso preparar el terreno para que de ellas pueda sacarse fruto. En esa perspectiva, es de no poca ayuda el testimonio vital que se presenta como ejemplo concreto de la realización de los verdaderos valores humanos, más todavía cuando vivir la ley natural a muchos les parece "antinatural", en el sentido de "poco realizable". Es así que la doctrina de la ley natural debe situarse en una perspectiva de diálogo donde ella tiene la posición más ventajosa, pues defiende los auténticos valores humanos. Aunque las tendencias sociales dominantes le sean contrarias, la ley natural defiende lo más hondamente humano que hay en toda experiencia, y por ello sus exigencias reaparecen con fuerza una y otra vez. De tal modo, quitadas las exageraciones y deformaciones de los principios de tolerancia y libertad, la ley natural aparece, justamente, como la fundamentación última de la dignidad humana y por consiguiente de la misma tolerancia y libertad. (Tonello 2011, 32-33) 


\section{Bibliografía}

Abbà, Giuseppe. 1995. Quale impostazione per la filosofía morale? Roma: LAS

Comisión Teológica Internacional. 2009. En busca de una ética universal: una nueva mirada sobre la ley natural. Buenos Aires: Conferencia Episcopal Argentina (Oficina del Libro).

Concilio Vaticano II, Constitución Pastoral Gaudium et Spes sobre la Iglesia en el mundo contemporáneo, del 7-XII-1965.

Cunningham, Lawrence (ed.). 2009. Intractable Disputes About the Natural Law. Alasdair MacIntyre and Critics. Notre Dame (IN): University of Notre Dame Press.

Francisco. 2015. Carta Encíclica Laudato Si'

Francisco. 2013. Exhortación Apostólica Evangelii Gaudium.

Francisco. 2016. Exhortación Apostólica Amoris Laetitia.

Gerardi, Renzo (ed.). 2007. La legge morale naturale. Roma: Lateran Universiy Press.

Galilei, Galileo. 1981. El ensayador. Buenos Aires: Aguilar.

Guardini, Romano. 1995. El fin de la modernidad. Madrid: PPC.

Herrera, Daniel (comp.). 2008. II Jornadas Internacionales de Derecho Natural. Ley natural y multiculturalismo. Buenos Aires: EDUCA.

MacIntyre, Alasdair. 1992. Tres versiones rivales de la ética. Madrid: Rialp.

MacIntyre, Alasdair. 1998. "Practical Rationalities as Forms of Social Structure”, en Knight, Kelvin (ed.). The MacIntyre Reader. Notre Dame (IN): University of Notre Dame Press.

Pérez-Soba, Juan José - Larrú, Juan - Ballesteros, Jaime (eds.). 2007. Una ley de libertad para la vida del mundo. Madrid: Actas del Congreso Internacional sobre la ley natural. Publicaciones de la Facultad de Teología "San Dámaso", Collectanea Matritensia 4.

Ratzinger, Joseph. 2016. Debate con Jürgen Habermas.

En http://mercaba.org/ARTICULOS/D/debate_Habermas_Ratzinger.htm> [consultado el 20-07-2016]. 
Ratzinger, Joseph. 2015. "La fraternidad cristiana”, en Obras Completas. Madrid: BAC.

Taylor, Charles. 1989. Sources of the Self. Cambridge (MA): Harvard University Press.

Santo Tomás de Aquino. Suma Teológica.

Tonello, Amadeo. 2011. El desafío de la ley natural. Tucumán: Ed. UNSTA.

Tonello, Amadeo. 2016. Artículo “Ley natural”, en Fernández Labastida, Francisco - Mercado, Juan Andrés, Philosophica: enciclopedia filosófica on line, disponible en $<$ http://www.philosophica.info/voces/ley_natural/Ley_natural.html $>$ [consultado el 20-07-2016]. ISSN electrónico 2035-8326. 